\title{
Monitoring the Thermal Efficiency of Fouled Heat Exchangers: A Simplified Method
}

M. A. S. Jerónimo

Qualena, Porto, Portugal

L. F. Melo

University of Minho, Center of

Biological Engineering / IBQF,

Braga, Portugal

A. Sousa Braga

P. J. B. F. Ferreira

C. Martins

Petrogal, Matosinhos, Portugal
- Fouling is a problem whether we are aware of it or not. In an industrial plant, it is important not only to be able to measure the buildup of unwanted deposits, but also to do it in the simplest and most economically possible way. This paper addresses the question of monitoring fouling in an oil refinery plant, where the high number of heat exchanger units and the variability of the feedstock charge pose additional problems in terms of the practicability of following the energetic performance of such equipment. In this case, the flow rates and quality of the fluids flowing through the heat exchangers do not usually correspond to the design conditions, because they change with time. Therefore, to assess the fouling level of the exchangers, the day-to-day measured thermal efficiency should not be compared with the efficiency predicted in the design calculations. The latter should be recalculated by introducing whenever necessary new values of flow rates, physical properties, and so forth, and by evaluating new heat transfer coefficients. However, the procedures are too time consuming to be applied frequently. The present work describes a simplified method for following heat exchanger performances, based on the assessment of the number of transfer units and thermal efficiencies, where the effects of changing the feedstock charge, particularly the flow rates of the fluids, are taken into account. The only data that need to be collected are the four inlet/outlet temperatures of the heat exchanger unit and one of the flow rates. Several heat exchanger units in an oil refinery were successfully monitored by means of this method, and it was found that the variations in the physical properties did not significantly affect the results obtained for the particular plant under study. (C) Elsevier Science Inc., 1997

Keywords: fouling; monitoring; heat exchangers

\section{INTRODUCTION}

Energy is a key parameter in the economics of any industry. Heat exchangers and heat exchanger networks are frequently used for the purpose of recovering heat and carrying out process integration to reduce energy consumption. In an oil refining plant, for instance, the amount of energy involved is enormous, and it is particularly important to be able to follow, in a realistic way, the performance of heat exchangers and their networks. The problem is even more accute on account of the well-known problem of fouling in oil refineries that affects heat transfer equipment. Simple and reliable monitoring methods should be available to enable production engineers to answer practical questions such as: What is the actual performance of the equipment at a given time of operation? Which is the ideal moment to stop the operation and clean the heat exchangers?
The level of fouling in a heat exchanger could be calculated by the following approximate expression, which gives the value of the fouling thermal resistance $\left(R_{\mathrm{f}}\right)$ :

$$
R_{\mathrm{f}}=\frac{1}{U}-\frac{1}{U_{\mathrm{o}}},
$$

where $U$ and $U_{\mathrm{o}}$ are the overall heat transfer coefficients at times $t>0$ (fouled exchanger) and $t=0$ (clean exchanger), respectively. In laboratory research work, conditions are kept stable, and the application of this equation is straightforward. This does not happen in most industrial cases. In fact, each time the operating conditions (such as fluid composition or flow rates or both) change with time, new values for the individual film coefficients and for $U_{\mathrm{o}}$ will have to be calculated and introduced in Eq. (1).

In an oil refinery, the high number of heat transfer units and the variability in the flow rates and composition 
of the raw material with time will imply modifying many variables in the equations used to evaluate $U$ and $U_{\mathrm{o}}$ to monitor the efficiency of heat exchangers, which becomes quite difficult in day-to-day operation. The goal of the present paper is to describe a methodology for following the fouling of heat exchangers by collecting a sufficient amount of information with the least possible effort; that is, by using measurement and calculation techniques that are not time consuming.

In a refinery plant in Portugal, the work started by trying to compare the daily thermal efficiency [evaluated by the usual equation; see Eq. (2)] with that assumed in the design of the heat exchanger unit. However, it was soon found that the values obtained were not representative of the actual fouling status of the equipment, which meant that some essential aspect was not being taken into consideration. A more careful analysis showed that, even when the feedstock charge was kept approximately constant, the deviations were correlated to the changes in the so-called heat capacity rate ratio of the two fluids. The "heat capacity rate" is defined here as the product of the mass flow rate and the specific heat of the fluid. That is, when the physical properties or the flow rates of the fluids or both changed, the calculation procedure had to be revised to take these changes into account. For such purposes, application of the traditional calculation methods led to a time-consuming effort that was not compatible with the economy of specialized human resources in the company.

A simplified method, based on the concepts of thermal efficiency and number of transfer units, was established with the purpose of obtaining the desired information on heat exchanger performances. The basic equations are presented in the next section and are further developed in the third section to account for the effect of variable mass flow rates.

\section{BASIC EQUATIONS}

\section{Single Heat Exchangers}

The thermal efficiency of a heat exchanger and the quotient of the heat capacity rates can be calculated when the inlet and outlet temperatures of the two fluids are known $[1,2]$. Let $T_{1}$ and $T_{2}$ be the inlet and outlet temperatures of the hot fluid, and $t_{1}$ and $t_{2}$ the inlet and outlet temperatures of the cold fluid. Then, if the heat capacity rate of the hot fluid is lower than the heat capacity rate of the cold fluid, the thermal efficiency $(E)$ is defined by

$$
E=\frac{T_{1}-T_{2}}{T_{1}-t_{1}} .
$$

The quotient of the heat capacity rates $(R=M C / m c$, where $M$ and $m$ are the mass flow rates and $C$ and $c$ are the specific heats of the hot and cold fluids, respectively) can be calculated in this case by

$$
R=\frac{t_{2}-t_{1}}{T_{1}-T_{2}} .
$$

The number of transfer units (referred to the hot fluid) is given by

$$
\mathrm{NTU}=U A /(M C),
$$

where $U$ is the overall heat transfer coefficient and $A$ the heat transfer area.

The above three variables are not independent: in fact, when the type of heat exchanger is given, the relation between them is readily obtained. Hence, for a countercurrent heat exchanger, the number of transfer units (NTU) is correlated with $E$ and $R$ through the following equation:

$$
\mathrm{NTU}=1 /(1-R) \ln [(1-E R) /(1-E)] \quad \text { if } R<1,
$$

and

$$
\mathrm{NTU}=E /(1-E) \quad \text { if } R=1 .
$$

In a $1-n$ exchanger (one pass through the shell and $n$ passes through the tubes), the following equation can be used [3]:

$$
\begin{gathered}
\mathrm{NTU}=\left(1 / C^{\prime}\right) \ln \left\{\left[2-E\left(R+1-C^{\prime}\right)\right] /\right. \\
\left.\left[2-E\left(R+1+C^{\prime}\right)\right]\right\}
\end{gathered}
$$

where

$$
C^{\prime}=\left(R^{2}+1\right)^{1 / 2}
$$

and

$$
R \leq 1
$$

The preceding equations can be solved explicitly in terms of the thermal efficiency $E$; that is,

For a countercurrent exchanger [4],

$$
E=\left(1-A^{\prime}\right) /\left(1-R A^{\prime}\right) \quad \text { if } R<1
$$

or

$$
E=\mathrm{NTU} /(1+\mathrm{NTU}) \text { if } R=1 \text {, }
$$

where

$$
A^{\prime}=\exp [-\mathrm{NTU}(1-R)]
$$

For a $1-n$ heat exchanger and $R \leq 1[3]$,

$$
E=2 /\left[1+R+\left(1+R^{2}\right)^{1 / 2}(1+B) /(1-B)\right],
$$

where

$$
B=\exp \left[-\mathrm{NTU}\left(1+R^{2}\right)^{1 / 2}\right]
$$

Similar expressions may be derived for the case where the heat capacity rate of the cold fluid is smaller than that of the hot fluid [2].

\section{Assembly of Identical Heat Exchangers}

For a series of $S$ identical heat exchangers of the $1-n$ type, the overall value of $R$ is the same as the value in one heat exchanger (here designated by $R^{*}$ ). The efficiency of any one of the heat exchangers $\left(E^{*}\right)$ can be obtained from the overall efficiency $(E)$ through [3]:

$$
E^{*}=(1-K) /(R-K) \text { if } R<1 \text {, }
$$

where

$$
K=[(1-E R) /(1-E)]^{1 / S}
$$

or

$$
E^{*}=E /(E-S E+S) \text { if } R=1 \text {. }
$$


Therefore, the value of $\mathrm{NTU}^{*}$ for one exchanger in the network can be obtained by replacing $E$ by $E^{*}$ in the expression developed for a $1-n$ exchanger [Eq. (7)].

The factor used to correct the $\log$ mean temperature difference in the design equation of heat exchangers can be considered the same for all identical $S$ exchangers. Then, the number of transfer units NTU* will also be the same in all identical exchangers.

Equations (14)-(16) can be solved in terms of the overall efficiency of the assembly of several heat exchangers $(E)$ :

$$
E=(1-L) /\left(R^{*}-L\right) \text { if } R^{*}<1,
$$

where

$$
L=\left[\left(1-E^{*} R^{*}\right) /\left(1-E^{*}\right)\right]^{S}
$$

or

$$
E=S E^{*} /\left[1-(1-S) E^{*}\right] \text { if } R=1 .
$$

Figures 1 and 2 illustrate two different situations that can occur when analyzing a series of heat exchangers. In Fig. 1 , the heat capacity rate of the assembly of two identical heat exchangers in series $(S=2)$ is the same as that of each of the exchangers: $(M C)^{*}=M C$ and $(m c)^{*}=m c$. Therefore, $R^{*}=R$. In Fig. 2 , the initial stream is divided into two streams, each one passing through a set of two heat exchangers in series as in Fig. 1. Thus, the values to be used in Eq. (17)-(19) will be: $S=2 ;(M C)^{*}=1 / 2$ $(M C) ;(m c)^{*}=1 / 2(m c) ; R^{*}=R$.

In actual operation, the heat capacity rate ratio may vary with time, and this causes changes in the efficiency. The number of transfer units of the heat exchanger also will vary with the operating conditions. In the next section, expressions are developed for estimating the changes in NTU caused by changes in the heat capacity rate ratio and in the flow rates of the fluids, supposing that their physical properties remain approximately constant. From the number of transfer units corresponding to the design conditions (which may or may not include the effect of the estimated fouling resistance), the number of transfer units and the efficiency of the actual operating conditions can be calculated, also incorporating the predicted fouling resistance. This efficiency may then be compared with the real efficiency obtained from the measured values of the four temperatures [see Eq. (2)] to estimate the actual fouling state of the exchanger.

\section{CALCULATION METHOD}

Thermal Resistances in Terms of Number of Transfer Units

Let $H$ and $h$ be the individual film coefficients of the hot and cold fluids, respectively. The overall heat transfer

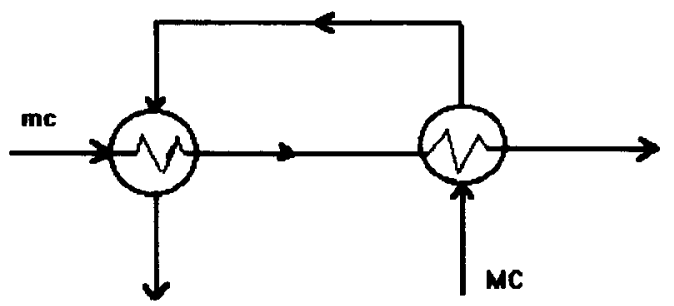

Figure 1. Two heat exchangers in series.

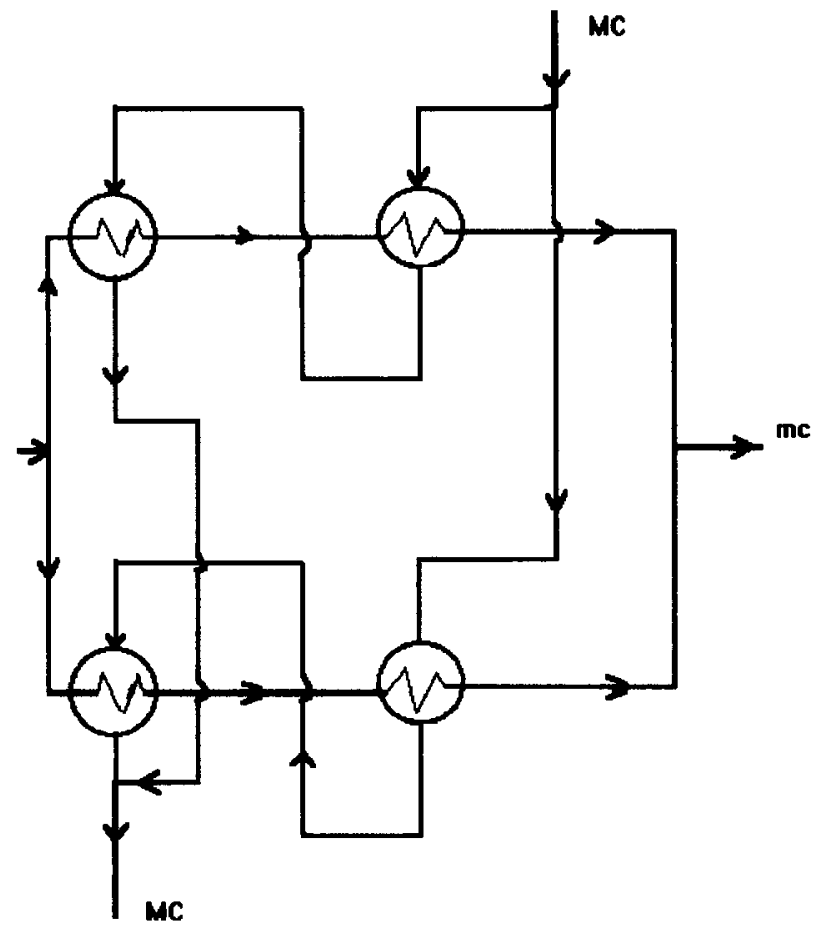

Figure 2. Assembly of four heat exchangers.

coefficient $U$ will be given by the well-known thermal resistance equation:

$$
1 /(U A)=1 /(H A)+1 /(h A),
$$

where the heat transfer coefficients of the hot and cold side are assumed to be already corrected by the effect of changing areas. The overall number of transfer units was defined in Eq. (4), taking the hot fluid as the reference fluid; however, if the heat capacity rate of the cold fluid is to be considered a reference, then the overall number of transfer units for the cold fluid (ntu) is calculated by means of

$$
\mathrm{ntu}=U A /(m c),
$$

where $m$ and $c$ are the mass flow rate and the specific heat of the cold fluid. The heat capacity heat ratio can be written, for each case, as follows: if $M C<m c$, then

$$
R=M C /(m c),
$$

and if $M C>m c$, then

$$
r=m c /(M C)=1 / R
$$

when either the hot fluid [Eq. (22)] or the cold fluid [Eq. (23)] is taken as the "reference fluid" (i.e., the fluid with the lowest heat capacity rate).

If we define the following individual number of transfer units based on the film heat transfer coefficients as

$$
\mathrm{NTU}_{\mathrm{H}}=H A /(M C)
$$

and

$$
\mathrm{ntu}_{\mathrm{h}}=h A /(m c),
$$


then Eq. (20) can be written as

$$
1 / \mathrm{NTU}=1 / \mathrm{NTU}_{\mathrm{H}}+R / \mathrm{ntu}_{\mathrm{h}}
$$

or

$$
1 / \text { ntu }=1 / \text { ntu }_{\mathrm{h}}+r / \mathrm{NTU}_{\mathrm{H}} .
$$

Therefore, it can be concluded that

$$
\mathrm{NTU}_{\mathbf{H}}=\mathrm{NTU}(H A) /(U A)
$$

and

$$
\mathrm{ntu}_{\mathrm{h}}=\mathrm{ntu}(h A) /(U A)
$$

\section{Effect of Mass Flow Rates on Number of Transfer Units}

The individual film heat transfer coefficients for turbulent flow inside tubes depend on the mass flow rate to the power 0.8 . In the shell side, the dependence is approximately 0.8 when the fluid flows parallel to the surface and 0.6 when the flow is perpendicular to the tube surfaces; therefore, the shell side heat transfer coefficients are here considered to be dependent on the flow rate to the power 0.7 .
The effect of the flow rate on the number of transfer units is illustrated below for several different cases:

(a) $R \ll 1$ : Typical case-boiling liquid. In this case, Eq. (26) reduces to $\mathrm{NTU} \approx \mathrm{NTU}_{\mathrm{H}}$ and $U \approx H$, meaning that $h \gg H$. The value of $h$ is not relevant in this case, because the limiting resistance is in the hot fluid side. Thus:

NTU $\sim(\mathrm{MC})^{-0.2}$ if the hot fluid flows inside the tubes

or

$$
\text { NTU } \sim(\mathrm{MC})^{-0.3} \text { if the hot fluid flows in the shell. }
$$

Therefore, when $R \ll 1$, the product NTU(MC) ${ }^{a}$ (with $a=0.2$ or 0.3 ) can be considered to be constant if the physical properties of the fluids do not change significantly.

(b) $r \ll 1$ : Typical case-condensing vapor. In this case, the product $n t u(m c)^{a}$ (with $a=0.2$ or 0.3 ) will be approximately constant.

(c) Countercurrent heat exchangers. Equation (26) is recommended when the major resistance is expected to be in the hot side. For this situation, the following
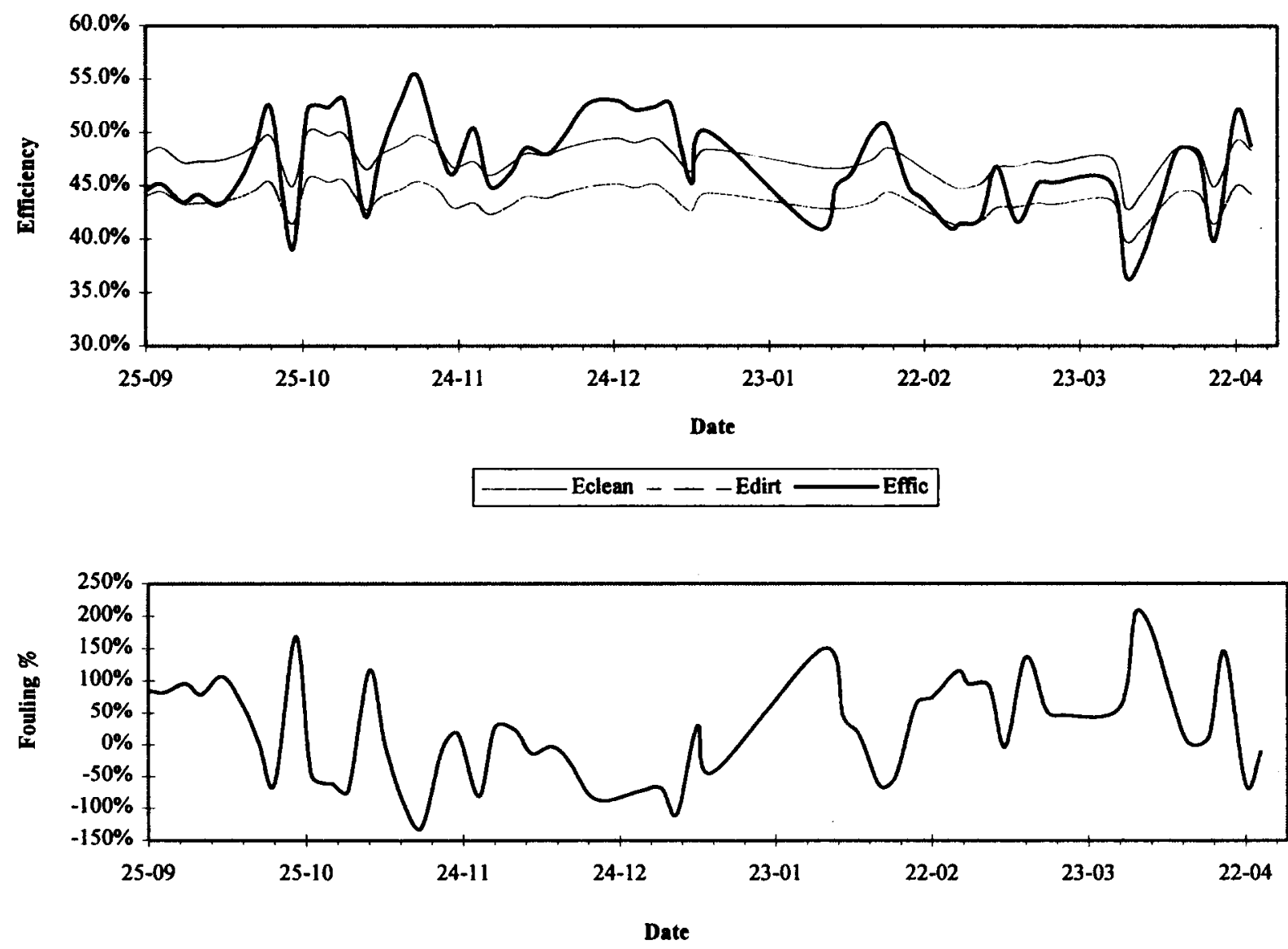

Figure 3. Thermal efficiency and fouling percentage of heat exchanger unit E-1 as a function of time. (a) No corrections due to the variability of the flow rates were introduced. $(b)$ Corrections due to the variability of flow rates were taken into account. 
equation can be written:

$$
\mathrm{NTU}(\mathrm{MC})^{0.2}=(\mathrm{NTU})_{\mathrm{d}}(M C)_{\mathrm{d}}^{0.2} / C_{\mathrm{f}},
$$

where "d" refers to the design conditions and

$$
C_{\mathrm{f}}=1+(U A / h A)_{\mathrm{d}}\left[\left(R / R_{\mathrm{d}}\right)^{0.8}-1\right] .
$$

Parameter $(U A / h A)_{\mathrm{d}}$ is equal to the quotient of the cold fluid and the total resistances predicted in the design of the exchanger. If the thermal resistance of the cold side is much lower than that of the hot side, $C_{\mathrm{f}}$ will approach unity; that is, case (a) will apply. Equation (31) can be linearized when the ratio $R / R_{\mathrm{d}}$ approaches 1 , resulting in:

$$
C_{\mathrm{f}}=1+0.8(U A / h A)_{\mathrm{d}}\left(R / R_{\mathrm{d}}-1\right) .
$$

In a similar way, when the major resistance is expected to be in the cold side, Eq. (27) is recommended. In this case,

$$
\mathrm{ntu}(m c)^{0.2}=(\mathrm{ntu})_{\mathrm{d}}(m c)_{\mathrm{d}}^{0.2} / c_{\mathrm{f}}
$$

where

$$
c_{\mathrm{f}}=1+(U A / H A)_{\mathrm{d}}\left(\left(r / r_{\mathrm{d}}\right)^{0.8}-1\right) .
$$

If the hot side resistance is much lower than the cold side resistance, $c_{\mathrm{f}}$ will tend to 1 and case (b) will apply. (d) Hot fluid in the shell with $R<1$. In this case,

$$
\mathrm{NTU}_{\mathrm{H}}(M C)^{0.3}=\left(\mathrm{NTU}_{\mathrm{H}}\right)_{\mathrm{d}}(M C)_{\mathrm{d}}^{0.3}
$$

and

$$
\mathrm{ntu}_{\mathrm{h}}(m c)^{0.2}=\left(\mathrm{ntu} \mathrm{u}_{\mathrm{d}}\right)_{\mathrm{d}}(m c)_{\mathrm{d}}^{0.2}
$$

Thus

$$
\mathrm{NTU}(M C)^{0.3}=(\mathrm{NTU})_{\mathrm{d}}(M C)_{\mathrm{d}}^{0.3} / C_{\mathrm{f}},
$$

where

$C_{\mathrm{f}}=1+(U A / h A)_{\mathrm{d}}\left[\left(R / R_{\mathrm{d}}\right)^{0.8}\left(M C /(M C)_{\mathrm{d}}\right)^{0.2}-1\right]$.

(e) Hot fluid in the tube side with $R<1$. In this case,

$$
\mathrm{NTU}_{\mathrm{H}}(M C)^{0.2}=\left(\mathrm{NTU}_{\mathrm{H}}\right)_{\mathrm{d}}(M C)_{\mathrm{d}}^{0.2}
$$

and

$$
\mathrm{ntu}_{\mathrm{h}}(m c)^{0.3}=\left(\mathrm{ntu}_{\mathrm{h}}\right)_{\mathrm{d}}(m c)_{\mathrm{d}}^{0.3}
$$

Thus

$$
\mathrm{NTU}(M C)^{0.2}=(\mathrm{NTU})_{\mathrm{d}}(M C)_{\mathrm{d}}^{0.2} / C_{\mathrm{f}},
$$

where

$C_{\mathrm{f}}=1+(U A / h A)_{\mathrm{d}}\left\{\left(R / R_{\mathrm{d}}\right)^{0.7}\left[M C /(M C)_{\mathrm{d}}\right]^{0.3}-1\right\}$.
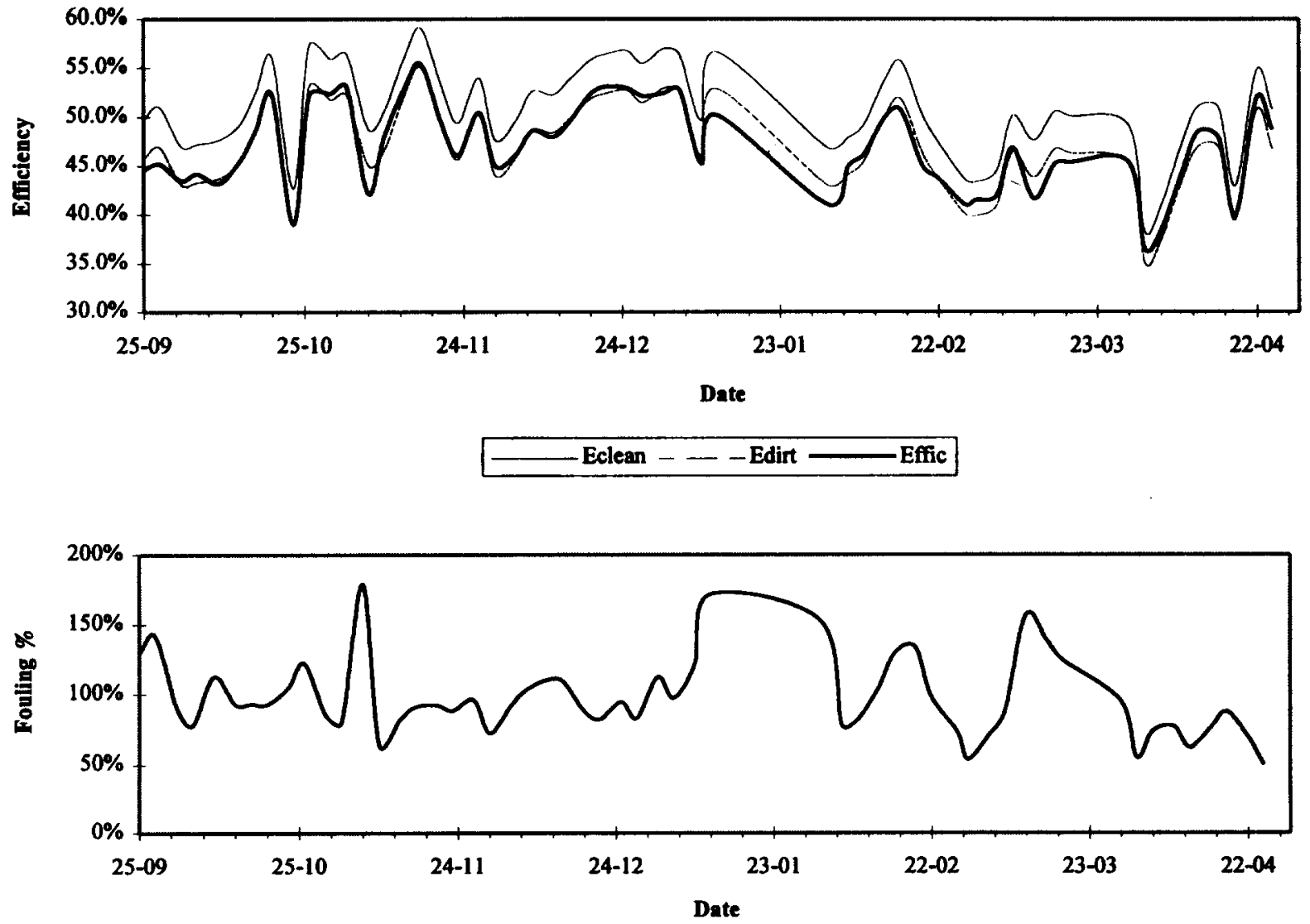

Figure 3b. Continued 
(f) Hot fluid in the shell side with $r<1$. Analogously,

$$
\mathrm{ntu}(m c)^{0.2}=(\mathrm{ntu})_{\mathrm{d}}(m c)^{0.2} / c_{\mathrm{f}},
$$

where

$$
c_{\mathrm{f}}=1+(U A / H A)_{\mathrm{d}}\left\{\left(r / r_{\mathrm{d}}\right)^{0.7}\left[m c /(m c)_{\mathrm{d}}\right]^{0.3}-1\right\} .
$$

(g) Hot fluid in the tube side with $r<1$.

$$
\operatorname{ntu}(m c)^{0.3}=(\mathrm{ntu})_{\mathrm{d}}(m c)^{0.3} / c_{\mathrm{f}},
$$

where

$$
c_{\mathrm{f}}=1+(U A / H A)_{\mathrm{d}}\left\{\left(r / r_{\mathrm{d}}\right)^{0.8}\left[m c /(m c)_{\mathrm{d}}\right]^{0.2}-1\right\} .
$$

When the flow rate of one of the fluids is the "feedstock charge," the flow rate of the other fluid can be related to the first one by using the following expressions, assuming that the specific heats do not change:

$$
m c /(m c)_{\mathrm{d}}=\left(R_{\mathrm{d}} / R\right) M C /(M C)_{\mathrm{d}}
$$

and

$$
M C /(M C)_{\mathrm{d}}=\left(r_{\mathrm{d}} / r\right) m c /(m c)_{\mathrm{d}} .
$$

In such a case, the feedstock charge is the only flow that needs to be known.

\section{RESULTS AND DISCUSSION}

As mentioned earlier, the main goal of this work was to develop a method of monitoring the performance of oil refinery heat exchangers without having to resort to timeconsuming simulations when flow rates and physical properties of the fluids change with time. The first attempt was to look at the effect of $R$ (or $r$ ) on the thermal efficiency, supposing that the number of transfer units remained constant; that is, by using the value of NTU (or ntu) assumed in the design calculations. In some cases, the results were satisfactory. However, when the feedstock charge was significantly different from that of the design, the measured day-to-day efficiency was either too low (the actual charge was higher than that of the design) or too high (the actual charge was lower than that of the design). Then, the effect of the flow rates on the number of transfer units had to be taken into account, using the equations described in the third section.

Figures 3-5 illustrate the adequacy of the method by showing the results obtained with some of the heat exchangers units. The top part of Fig. $3 a$ presents the evolution of the thermal efficiencies of heat exchanger unit E-1 calculated without taking into account the effect of the flow rates and compares them with the actual measured efficiency.

The "fouling percentage" curve in the bottom part of Fig. $3 a$ (as well as in Figs. 4 and 5) is obtained from the following expression:

$$
\text { Fouling } \%=\left(E_{\text {clean }}-\text { Effic }\right) /\left(E_{\text {clean }}-E_{\text {dirt }}\right) 100,
$$

where $E_{\text {clean }}$ is the thermal efficiency predicted for a clean heat exchanger; $E_{\text {dirt }}$ is the thermal efficiency calculated
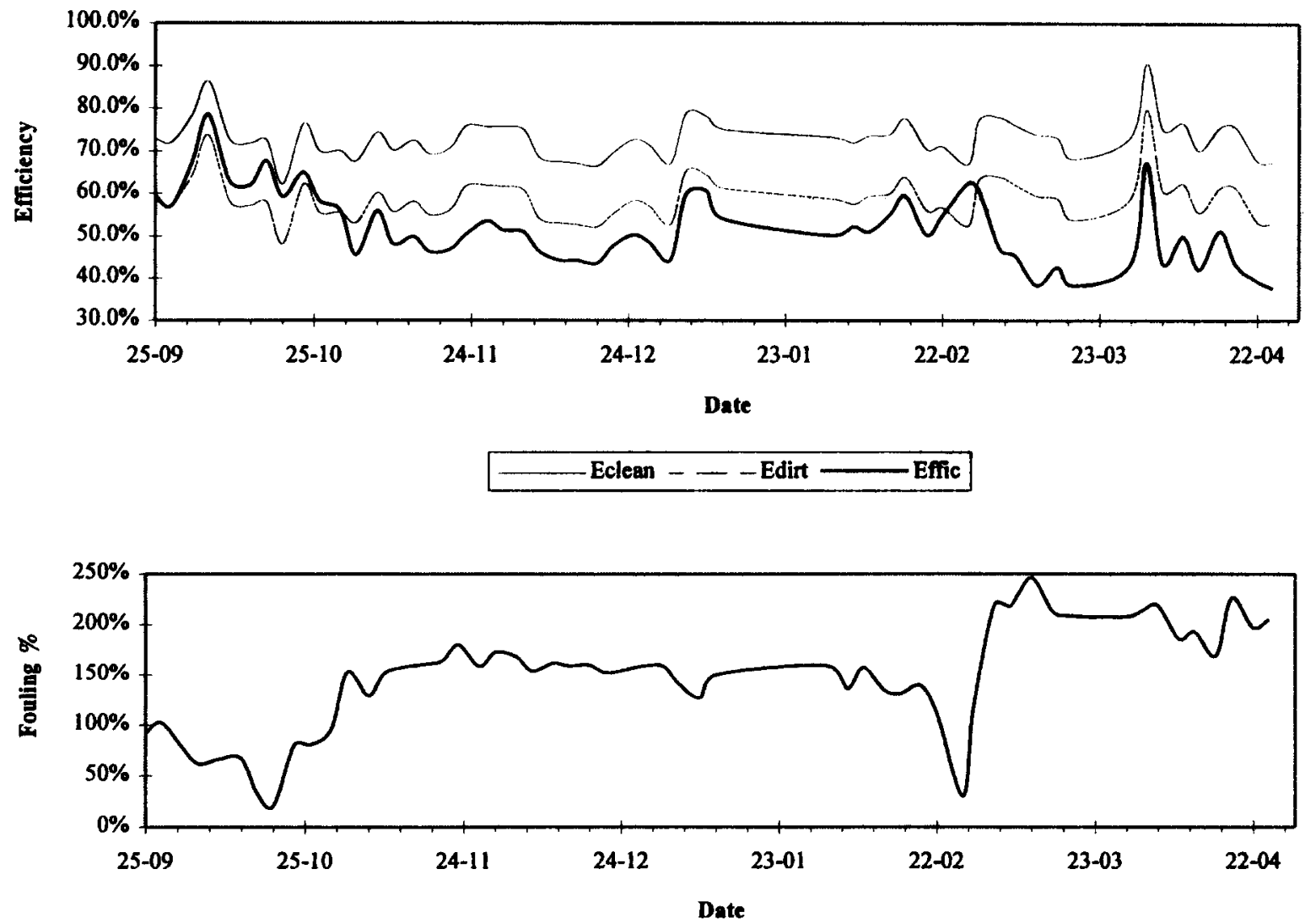

Figure 4. Thermal efficiency and fouling percentage of heat exchanger unit E-2 as a function of time. Corrections due to the variability of flow rates were taken into account. 

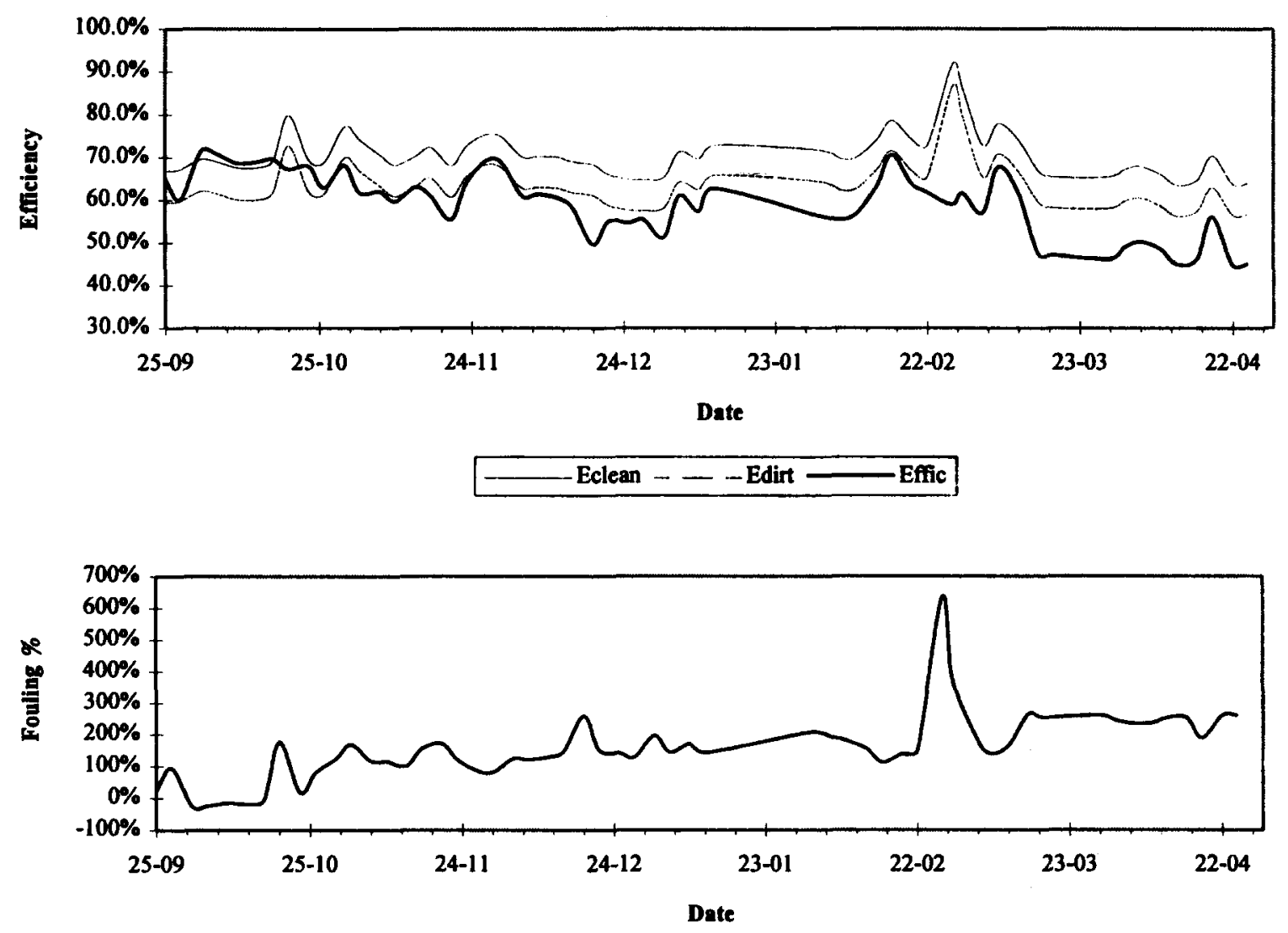

Figure 5. Thermal efficiency and fouling percentage of heat exchanger unit E-3 as a function of time. Corrections due to the variability of flow rates were taken into account.

by assuming an "expected" fouling resistance; and Effic is the measured thermal efficiency (based on the actual measured values of the four temperatures at the inlet and outlet of the exchangers), which is exactly the same as $E$ in $\mathrm{Eq}$. (2).

Although the effects caused by changes in $R$ (or $r$ ) were considered, it is obvious that the calculated efficiencies ("clean" or "dirt") do not fit the measured efficiency (Effic). In fact, not only are their absolute values far from the real ones (and this could be simply caused by a failure in predicting the true fouling resistance), but also the trends of the calculated and measured curves are quite distinct.

When the correction due to the flow rate variability is introduced in the calculated efficiences (Fig. $3 b$ ), the result is quite satisfactory. In fact, the measured efficiency (Effic) and the calculated efficiency, including fouling effects $\left(E_{\text {dirt }}\right)$, have identical values throughout the period of time shown in Fig. $3 b$. The only exception is the period between December and January, which follows a stop in the operation of the heat exchanger unit. The predicted fouling resistance appears to be quite realistic in this case. It should be stressed that, although the possible changes in the physical properties of the fluids during operation were not considered throughout this work, they do not seem to be significant in the final result.

The "fouling percentage" at the bottom of Fig. $3 b$ fluctuates about a constant value (in spite of a few erratic points), mainly during the first four months. The first date shown in Figure $3 b$ does not correspond to the start-up of the unit after cleaning, which explains why there already is an established "plateau" in the fouling curve.

Figures 4 and 5 present two other cases where the effect of flow rate variability was taken into account. In Fig. 4 (heat exchanger unit E-2), the calculated efficiencies follow the trend of the measured efficiency quite well, but their values are different, indicating that the exchangers were designed for more favorable conditions (Effic is lower than $E_{\text {dirt }}$ ).

Later on, after a stop in February, there was a decrease in the fouling percentage, owing to detachment caused by the "hydraulic shock" when restarting the flow followed by a rapid increase to a higher value of the fouling plateau (200\%). This phenomenon had been reported by others [5], who carried out carefully controlled laboratory experiments. The increased temperatures that may have developed on the surface of the deposit during the break in operation could explain the higher amount of fouling detected afterward.

Finally, Fig. 5 presents a heat exchanger unit (E-3) where the fouling percentage increases more gradually with time, taking about six months to reach the final plateau. Once again, the calculated efficiency closely follows the trend of the measured efficiency (top part of Fig. 5). In this case, the initial date (September 25) coincides with the start-up of the unit after cleaning. 
Table 1. Thermal Efficiencies of the Heat Exchanger Units

\begin{tabular}{|c|c|c|c|}
\hline \multirow[b]{2}{*}{ Unit No. } & \multicolumn{2}{|c|}{ Predicted Efficiencies } & \multirow{2}{*}{$\begin{array}{c}\text { Measured } \\
\text { Efficiencies } \\
\text { (Final Values- } \\
\text { Average) }\end{array}$} \\
\hline & $\begin{array}{c}\text { Clean } \\
\text { Exchanger }\end{array}$ & $\begin{array}{c}\text { Fouled } \\
\text { Exchanger }\end{array}$ & \\
\hline E-1 & $46.4 \%$ & $42.7 \%$ & $43 \%$ \\
\hline $\mathrm{E}-2$ & $87.3 \%$ & $75.1 \%$ & $44 \%$ \\
\hline E-3 & $66.7 \%$ & $59.3 \%$ & $47 \%$ \\
\hline
\end{tabular}

Table 1 gives the values of the thermal efficiency predicted in the design calculations for the three units, under clean and fouled conditions, together with rough average values of the actual measured efficiencies during the last weeks of operation, as shown in Figs. 3-5.

The predicted thermal efficiencies of the fouled exchangers are, in general, higher than the measured ones, except for unit E-1, where the values are similar. This means that the actual operating conditions are more severe with regard to fouling than those expected when the equipment was designed. It should be noted that, in spite of the similar values found for unit E-1, the true operating conditions were not the same as those of the design: the predicted flow rate was $9700 \mathrm{~kg} / \mathrm{h}$ for that unit; but, by the end of September, it had reached approximately 11,000 $\mathrm{kg} / \mathrm{h}$; after that, it decreased to $7300 \mathrm{~kg} / \mathrm{h}$ by the middle of November and even reached $5800 \mathrm{~kg} / \mathrm{h}$ by the end of November, before increasing again three days later. Thus, the flow rate variations are not only substantial, but also very frequent, and this certainly emphasizes the need for simple methods to follow the thermal performance of the heat exchanger and to compare it with the performance it should have if there were no fouling problems.

\section{CONCLUSIONS}

In many industrial situations, the flow rates or the composition of the fluids (or both) vary with time, and the value of the overall heat transfer coefficient representative of the clean exchanger under each particular operating condition $\left(U_{\mathrm{o}}\right)$ also is constantly changing. As a consequence, the daily evaluation of heat exchanger performances through Eq. (1) would require a significant effort in introducing new values for the physical properties and fluid velocities into the computer programs, as well as a large amount of computing time.

To avoid such cumbersome calculations, the method described here relies upon two simple mathematical procedures: (1) determination of the measured efficiency (Effic) by using the actual values of the four inlet and outlet fluid temperatures in the heat exchanger; and (2) calculation of the estimated efficiencies of the exchanger ( $E_{\text {dirt }}$ and $E_{\text {clean }}$ ) by taking into account the changes in $R$ (or $r$ ) and in the flow rates, which in turn are reflected in the value of the number of transfer units. The equations derived for this purpose are much simpler to use than those needed to calculate changes in $U_{\mathrm{o}}$.

The experimental values obtained in industrial units showed that the effects of $R$ (or $r$ ) and flow rates have to be considered and that the effects of variable physical properties are not important, at least in the case of the particular oil refinery where this study was carried out. Nevertheless, even in a lubricating oil plant where the stock quality changed periodically, this method was applied with success.

In spite of its simplifying assumptions, the method yields fairly good results in the monitoring of heat exchanger units and in the assessment of their fouling condition. Obviously, the method should be applied with care in cases where the heat exchangers process various fluids, with significantly distinct physical properties at different times.

\section{NOMENCLATURE}

$A$ heat transfer area, $\mathrm{m}^{2}$

$A^{\prime}$ parameter defined by Eq. (11), dimensionless

$B$ parameter defined by Eq. (13), dimensionless

$C$ specific heat of the hot fluid, $\mathrm{J} /(\mathrm{kg} \mathrm{K})$

$c$ specific heat of the cold fluid, $\mathrm{J} /(\mathrm{kg} \mathrm{K})$

$C^{\prime}$ parameter defined in Eq. (8), dimensionless

$C_{\mathrm{f}}$ parameter defined in Eq. (31), dimensionless

$c_{\mathrm{f}}$ parameter defined in Eq. (34), dimensionless

$E$ measured thermal efficiency of the heat exchanger [see Eq. (2)], dimensionless

$E_{\text {clean }}$ thermal efficiency predicted for the clean heat exchanger, dimensionless

$E_{\text {dirt }}$ thermal efficiency predicted for the fouled heat exchanger, assuming an "expected" fouling resistance, dimensionless

Effic $(=E)$ measured efficiency of the heat exchanger, dimensionless

$h$ film heat transfer coefficient of the cold fluid, $\mathrm{W} /\left(\mathrm{m}^{2} \mathrm{~K}\right)$

$H$ film heat transfer coefficient of the hot fluid, $\mathrm{W} /\left(\mathrm{m}^{2} \mathrm{~K}\right)$

$K$ parameter defined by Eq. (15), dimensionless

$L$ parameter defined by Eq. (18), dimensionless

$M$ mass flow rate of the hot fluid, $\mathrm{kg} / \mathrm{s}$

$m$ mass flow rate of the cold fluid, $\mathrm{kg} / \mathrm{s}$

NTU overall number of heat transfer units referred to the heat capacity of the hot fluid, dimensionless

$\mathrm{NTU}_{\mathbf{H}}$ individual number of heat transfer units, based on the film heat transfer coefficient of the hot fluid, dimensionless

ntu overall number of heat transfer units referred to the heat capacity of the cold fluid, dimensionless

$\mathrm{ntu}_{\mathrm{h}}$ individual number of heat transfer units, based on the film heat transfer coefficient of the cold fluid, dimensionless

$R$ heat capacity rate ratio between the hot and the cold fluids, dimensionless

$r$ heat capacity rate ratio between the cold and the hot fluid $(r=1 / R)$, dimensionless

$R_{\mathrm{f}}$ thermal resistance of the deposit, $\mathrm{m}^{2} \mathrm{~K} / \mathrm{W}$

$S$ number of identical heat exchangers in series, dimensionless

$U$ overall heat transfer coefficient at time $t>0$ $\mathrm{W} /\left(\mathrm{m}^{2} \mathrm{~K}\right)$

$U_{\mathrm{o}}$ overall heat transfer coefficient at time $t=0$ $\mathrm{W} /\left(\mathrm{m}^{2} \mathrm{~K}\right)$ 
d design conditions

\section{Subscript}

Superscript

* single heat exchanger (in a series of heat exchangers)

\section{REFERENCES}

1. Ozisik, M. N., Heat Transfer: A Basic Approach. International Student Edition, McGraw-Hill, 1985.

2. Kakaç, S., and Agrawal, A. K., Basic Relationships for Heat Exchangers and Impact of Fouling in Design. In Fouling Science and Technology, L. F. Melo, T. R. Bott, and C. A. Bernardo, Eds., pp. 437-462, Kluwer, Dordrecht, Netherlands, 1988.
3. Dodd, R., Mean Temperature Difference and Temperature Efficiency for Shell-and-Tube Heat Exchangers Connected in Series with Two Tube Passes for Shell Pass. Trans. I. Chem. Eng. 58, 9-15, 1980.

4. London, A. L., and Seban, R. A., A Generalization of the Methods of Heat Exchanger Analysis. Int. J. Heat Mass Transfer, 23, 5-16, 1980.

5. Crittenden, B., and Kolaczkowski, S., Mass Transfer and Chemical Kinetics in Hydrocarbon Fouling. Conf. on Fouling: Art or Science? Univ. Surrey, p. 169, 1979.

Received April 17, 1996; revised August 30, 1996 